Authors' Contribution:

A Study Design

B Data Collection

C Statistical Analysis

D Data Interpretation

E Manuscript Preparation

F Literature Search

G Funds Collection

\section{Self-regulation strategies used by men and women attending to fitness clubs}

\author{
Krzysztof Sas-Nowosielski ${ }^{A C D E}$, Sylwia Szopa ${ }^{\mathrm{BF}}$ \\ The Jerzy Kukuczka Academy of Physical Education in Katowice, Poland
}

abstract

Background

Material/Methods

Results

Conclusions

Key words
The purpose of this study was to examine the self-regulation strategies used by men and women attending to fitness clubs and how they are related to the level of participants' physical activity.

The participants of the study were 200 persons attending fitness clubs, including 108 women (54\%) and 92 men (46\%), aged 17-63 years, mean $29.18 \pm 9.16$ years. The questionnaire measuring self-regulation strategies: goal-setting, self-monitoring, enlisting social support, self-rewarding and stimulus control were used along with Godin Leisure-Time Exercise Questionnaire assessing physical activity.

Participants exercised on average 6.17 ( \pm 3.83 ) hours MVPA weekly. From the self-regulation strategies the most frequently used was goal setting. The differences between men and women were observed only in enlisting social support $(\mathrm{t}(198)=2.92, \mathrm{p}=0.004, \mathrm{~d}=$ $0.41)$ and self-rewarding $(\mathrm{t}(198)=3.30, \mathrm{p}=0.001, \mathrm{~d}=0.48)$ which - in both sexes - are more frequently used by women. Regression analyses revealed that in both sexes goal setting was the strongest predictor of the level of exercise (men $\beta=0.32$, women $\beta=0.42$ ) and in women additionally enlisting social support $(\beta=-0.23)$.

Self-regulation strategies may be effective tool in maintaining exercise, however their use is moderate. Most frequently used is goal setting, while others are used occasionally. It would be worth to educate exercises on the possibilities of regulating their own exercise behaviors.

self-regulation, physical activity, motivation

\section{article details}

Article statistics

Full-text PDF:

Copyright

Indexation:

Funding:

Conflict of interest: Corresponding author:

Open Access License:
Word count: 1,965; Tables: 3; Figures: 0; References: 13

Received: April 2015; Accepted: July 2015; Published: September 2015

http://www.balticsportscience.com

(๑) Gdansk University of Physical Education and Sport, Poland

AGRO, Celdes, CNKI Scholar (China National Knowledge Infrastructure), CNPIEC, De Gruyter - IBR (International Bibliography of Reviews of Scholarly Literature in the Humanities and Social Sciences), De Gruyter - IBZ (International Bibliography of Periodical Literature in the Humanities and Social Sciences), DOAJ, EBSCO - Central \& Eastern European Academic Source, EBSCO - SPORTDiscus, EBSCO Discovery Service, Google Scholar, Index Copernicus, J-Gate, Naviga (Softweco, Primo Central (ExLibris), ProQuest - Family Health, ProQuest - Health \& Medical Complete, ProQuest - Illustrata: Health Sciences, ProQuest - Nursing \& Allied Health Source, Summon (Serials Solutions/ProQuest, TDOne (TDNet), Ulrich's Periodicals Directory/ulrichsweb, WorldCat (OCLC)

This research received no specific grant from any funding agency in the public, commercial, or not-for-profit sectors.

Authors have declared that no competing interest exists.

Dr hab. Krzysztof Sas-Nowosielski, prof. nadzw., Katedra Humanistycznych Podstaw Kultury Fizycznej, Akademia Wychowania Fizycznego w Katowicach, ul. Mikołowska 72b,40-065 Katowice, tel. (32) 207 5320,

e-mail: k.sas-nowosielski@awf.katowice.pl

This is an open access article distributed under the terms of the Creative Commons Attribution-Non-commercial 4.0 International (http://creativecommons.org/licenses/by-nc/4.0/), which permits use, distribution, and reproduction in any medium, provided the original work is properly cited, the use is non-commercial and is otherwise in compliance with the license. 


\section{INTRODUCTION}

There is no doubt that regular physical activity exerts a positive influence on all aspects of human health - physical, mental and social [1, 2]. Common consciousness of these benefits prompts health authorities to extensive efforts aiming at promoting physical activity among people. However, it should be remembered that taking up physical activity by a person is only the first step because it does not guarantee long term, and preferably life-long, involvement in physical activity, which is the much-desired behavioral pattern. Many people that became regular exercisers go back or relapse to physical inactivity [3]. Most relapses occur within the first few months from the starting point of regular exercise program [4]. The reason behind relapses is probably related to the complicated nature of physical activity, as it is - unfortunately - that kind of behaviors the cost of which are borne immediately (for example physical exertion with all related physical and psychological sensations, like muscle pain or tiredness), while the benefits (better health, fitness) are experienced after long time.

In order to be in a position to continue their commitment in desired behaviors, people consciously and unconsciously use varied cognitive and behavioral mechanisms, which are collectively termed as self-regulation or self-motivation [5, 6]. The notion of self-regulation has no precise and explicit definition. It is rather an umbrella-term and "refers broadly to efforts by humans to alter their thoughts, feelings, desires, and actions in the perspective of such higher goals [7, p. 2] or, according to Knapp, "a learned set of skills and habitual responses that function to assist individuals to adhere to activities that are not adequately cued and reinforced by the environment or that may even be punished" [8, p. 220]. They include, among others, goal setting, enlisting social support, self-rewarding and other forms of stimulus control, and in people at the initial stages of making behavior change also gathering knowledge on the desired behavior (benefits, possibilities of undertaking etc.). People with high self-regulation abilities are more prone to undertaking health behaviors and more successful in turning behavioral intentions into real actions [7].

The purpose of the study was twofold: diagnostic and explanatory. The diagnostic purpose related to finding what self-regulation strategies are most frequently used by men and women attending fitness centers. The explanatory purpose was to define how specific strategies are related to the level of the participants' physical activity.

\section{MATERIAL AND METHODS}

The data for this study were collected from 200 persons attending fitness centers, including 108 women (54\%) and 92 men (46\%), aged 17-63, mean $29.18 \pm 9.16$ years. Each participant completed a questionnaire consisting of a series of nineteen statements rated on the Likert scale from 1 (never) to 5 (regularly) and relating to five self-regulation strategies: goal setting (defining and establishing goals a person wants to attain in his/her body build, patterns of behavior etc.), enlisting social support (looking for and getting in touch with other exercisers who can serve as motivators, advisers, supporters), self-rewarding (bringing oneself some pleasure when the planned change is achieved), stimulus control (modifying proximal environment in a manner 
that increases a probability of undertaking desired behaviors, for example removing from one's flat things that encourage sedentary behaviors and/or adding things that remind of and encourage to physical activity), self-monitoring (tracking one's behaviors) and gathering information (actions aimed at better understanding problems related to sedentary lifestyle and increasing knowledge what for and how to be physically active).

To examine the theoretical validity, factor analysis using the Maximum Likelihood Method was conducted. Both criteria, Cattel (establishing the number of factors based on a screen plot) and Kaiser (establishing the number of factors on the basis of factor loadings) suggested an exclusion of the "gathering knowledge" factor. The remaining factors reached eigenvalues over 1 and accounted for $63 \%$ variance.

The reliability of the measure was assessed by a method of internal consistency using Cronbach's alpha coefficient. According to Sokolowski and Sagan [9], the minimum the border value of alpha is 0.60 , although one should rather strive for alpha values of 0.70 as the threshold of acceptable reliability. All measures, apart from abovementioned fathering knowledge, reached the threshold: enlisting social support $\alpha=0.75$, self-rewarding $\alpha=0.77$, goal setting $\alpha=0.77$, stimulus control $\alpha=0.79$, self-monitoring $\alpha=0.72$.

Physical activity was assessed with Godin's Leisure-Time Exercise Questionnaire (GLTEQ). The subjects' task was to report how many times in previous week and how long each time they were physically active on the moderate and vigorous level. Each category was described in a way understandable for participants with examples of exercises and forms of physical activity.

Assumption for normality was assessed by skewness and kurtosis taking as a rule of thumb that a variable is reasonably close to normal if its skewness and kurtosis have values between -1.0 and +1.0 . Skewness of all variables ranged between -0.12 and 0.95 . The range of kurtosis was between -0.01 to -0.78 , with one exception in the case of enlisting social support, kurtosis of which was 3.0. The homogeneity of the variance was assessed by Levene's test and all variables met the criterion. To assess differences between male and female participants t test was used and next the effect size was calculated by Cohen's d formula. Values of small, moderate and large strength of association d-values of $0.20,0.50$ and 0.80 was taken as a border [10].

To assess a supposed influence of self-regulation strategies on physical activity level, regression analysis was made. All analyses were conducted in Statistica 10 (Statsoft) software.

\section{RESULTS}

The level of moderate-to-vigorous physical activity (MVPA) level was $6.17( \pm 3.83)$ hours a week for the entire group. However, a significant difference between males and females were observed, with a higher level of MVPA in the former (respectively, $7.23 \pm 3.37$ hours and $5.27 \pm 4.08$ hours; $\mathrm{t}(198)=-3.71, \mathrm{p}<0.001$, $\mathrm{d}=0.52)$.

The highest score in the self-regulation strategies was observed in goal setting, suggesting that this strategy is most frequently used by fitness centers users. The 
mean of goal setting was significantly different from all the remaining ones. The lowest score was observed in stimulus control; however, it was statistically lower only from goal setting and self-monitoring. The exact data of descriptive statistics are shown in Table 1 and the correlation matrix between variables in Table 2.

Table 1. Descriptive statistics (mean, SD) for self-regulation strategies for all participants and separately for males and females with differences between both sexes

\begin{tabular}{|c|c|c|c|c|c|c|c|c|c|}
\hline & \multicolumn{2}{|c|}{ Total sample } & \multicolumn{2}{|l|}{ Female } & \multicolumn{2}{|l|}{ Male } & \multicolumn{3}{|c|}{$\begin{array}{c}\text { Male/female } \\
\text { differences }\end{array}$} \\
\hline & $\bar{x}$ & SD & $\bar{x}$ & SD & $\bar{x}$ & SD & $t_{(198)}$ & $\mathrm{p}$ & $d$ \\
\hline Social support & $2.64^{a}$ & 1.20 & 2.87 & 1.32 & 2.38 & 1.00 & 2.92 & 0.004 & 0.41 \\
\hline Self-rewarding & $2.69^{b}$ & 0.90 & 2.88 & 0.83 & 2.46 & 0.94 & 3.30 & 0.001 & 0.48 \\
\hline Goal setting & $3.33^{\mathrm{abcd}}$ & 1.08 & 3.26 & 0.96 & 3.40 & 1.20 & -0.93 & 0.35 & -0.01 \\
\hline Stimulus control & $2.59^{c e}$ & 0.91 & 2.54 & 0.87 & 2.64 & 0.96 & -0.85 & 0.397 & -0.001 \\
\hline Self-monitoring & $2.86^{\text {de }}$ & 1.19 & 2.79 & 1.17 & 2.93 & 1.21 & -0.85 & 0.398 & -0.004 \\
\hline
\end{tabular}

Means with the same superscript were significantly different $(p<0.05)$

Table 2. Correlation matrix between the variables

\begin{tabular}{|c|c|c|c|c|c|c|}
\hline & 1 & 2 & 3 & 4 & 5 & 6 \\
\hline \multicolumn{7}{|l|}{1 Age } \\
\hline 2 MVPA & $-0.23 *$ & & & & & \\
\hline 3 Social support & $0.23 *$ & $-0.22 *$ & & & & \\
\hline 4 Self-rewarding & $0.18^{*}$ & -0.09 & $0.55^{*}$ & & & \\
\hline 5 Goal setting & $-0.18 *$ & $0.38 *$ & 0.02 & $0.26 *$ & & \\
\hline 6 Self-monitoring & 0.06 & $0.22 *$ & 0.02 & $0.19 *$ & $0.48^{*}$ & \\
\hline 7 Stimulus control & $0.24 *$ & 0.13 & $0.29 *$ & $0.44 *$ & $0.40 *$ & $0.72 *$ \\
\hline
\end{tabular}

MVPA: moderate-to-vigorous physical activity

Male and female participants differed significantly in the frequency of using two strategies: enlisting social support (respectively, $\bar{x}=2.87 \pm 1.32$ and $\bar{x}=2.38$ $\pm 1.03, \mathrm{t}(198)=2.92, \mathrm{p}=0.004, \mathrm{~d}=0.41)$ and self-rewarding (respectively, $\overline{\mathrm{x}}=$ $2.88 \pm 0.83, \bar{x}=2.46 \pm 0.94, \mathrm{t}(198)=3.30, \mathrm{p}=0.001, \mathrm{~d}=0.48)$. For both sexes separate regression models were tested with physical activity as a depend-ent variable and self-regulation strategies as predictors. Both models were significant: males $\mathrm{R}=0.35, \mathrm{R}^{2}=0.12, \mathrm{~F}(5,86)=2.37 \mathrm{p}=0.046$; females $\mathrm{R}=0.55$; $\mathrm{R}^{2}=0.30 ; \mathrm{F}(5,102)=8.92 \mathrm{p}<0.001$. In both sexes the level of physical activity was predicted by goal setting (males $\beta=0.32$, females $\beta=0.42$ ) and in females additionally by social support ( $\beta=-0.23$ ). In the latter a tendency toward significance was observed in another predictor - stimulus control. Results of regression analyses are summarized in Table 3. 
Table 3. Multiple regression analyses summary for self-regulation strategies as predictor variables of the level of physical activity of male and female participants

Males $R=0.35, R^{2}=0.12, F_{(5,86)}=2.37 p=0.046$

\begin{tabular}{lllllll}
\hline & $\beta$ & SE $\beta$ & $B$ & SEB & $t(86)$ & $p$ \\
\hline Social support & -0.06 & 0.14 & -0.24 & 0.56 & -0.42 & 0.674 \\
\hline Self-rewarding & -0.02 & 0.15 & -0.08 & 0.64 & -0.13 & 0.899 \\
\hline Goal setting & 0.33 & 0.12 & 1.13 & 0.41 & 2.79 & 0.007 \\
\hline Stimulus control & -0.16 & 0.17 & -0.70 & 0.72 & -0.98 & 0.330 \\
\hline Self-monitoring & 0.11 & 0.15 & 0.37 & 0.51 & 0.71 & 0.477 \\
\hline
\end{tabular}

Females $R=0.55 ; R^{2}=0.30 ; F_{(5,102)}=8.92 p<0.001$

\begin{tabular}{lllllll}
\hline & $\beta$ & SE $\beta$ & $\mathrm{B}$ & $\mathrm{SEB}$ & $\mathrm{t}(102)$ & $\mathrm{p}$ \\
\hline Social support & -0.23 & 0.10 & -0.60 & 0.25 & -2.38 & 0.019 \\
\hline Self-rewarding & -0.13 & 0.10 & -0.52 & 0.41 & -1.25 & 0.214 \\
\hline Goal setting & 0.42 & 0.10 & 1.46 & 0.34 & 4.32 & $<0.001$ \\
\hline Stimulus control & 0.27 & 0.15 & 1.04 & 0.56 & 1.84 & 0.068 \\
\hline Self-monitoring & -0.10 & 0.14 & -0.28 & 0.41 & -0.67 & 0.502 \\
\hline
\end{tabular}

\section{DISCUSSION}

The purpose of this study was to assess which self-regulation strategies are used by males and females exercising in fitness centers and how these strategies are related to participants' physical activity level. The results suggest that the most frequently used self-regulation strategy in both sexes is goal setting. It is defined as setting for oneself some desired, but not existent states of body shape, body mass and/or frequency of behaviors, which at some point of time have to become real aspects of appearance or behavior. Goal setting is considered as one of the most successful self-regulation strategies $[4,6,11]$, and among numerous benefits relating to using it are, for example, according to Leitner and Leitner [12], gaining perspective on what is most important in life, providing a sense of direction and purpose, gaining a sense of personal control over circumstances, facilitating greater achievements. Therefore, the fact that goal setting is the most frequently used self-regulation strategy could be seen positively. However, on the other hand, it should be considered that, firstly, the obtained mean valued for this strategy could be verbalized as a frequency occasional-to-frequent, so it is not common, secondly, it should be kept in mind that the real motivating value of the goals set for oneself is largely dependent on the way they were formulated (according to principles known as SMART: specific, measurable, achievable, realistic and time-framed) $[4,13]$. The latter aspect may vary from person to person but this aspect was not assessed in our study.

The rare use of the remaining strategies may be related to unawareness of their existence by many exercisers or at least not considering using them for one's purposes. Within these rather occasionally used strategies two differences between male and female exercisers were observed - females are more prone to self-reward their exercise behaviors and to enlist social support, in both cases with moderate size of the difference between sexes. 
While goal setting was a predictor of the physical activity level in both sexes, in females social support was an additional predictor, and in the case of stimulus control a tendency toward a significant influence was observed. Interestingly, the relationship between behaviors and the second of the aforementioned strategies was negative. This, a little surprisingly, result may be interpreted as the greatest demand for support from others in less extensively exercising females.

\section{CONCLUSIONS}

In conclusion, the results of this study suggests that cognitive and behavioral strategies with the aid of which people could regulate their own behaviors may be helpful for people exercising in fitness clubs in order to be more active. Among them goal setting is used the most frequently.

Of course, some limitations of the study should also be mentioned when interpreting its results. Firstly, the cross-sectional design limits the possibilities to draw conclusions on the cause-and-effect associations between the variables. Secondly, self-reported measures, including especially physical activity, may be susceptible to response bias.

\section{REFERENCES}

[1] Dishman RK, Washburn RA, Heath GW. Physical activity epidemiology. Champaign: Human Kinetics; 2004.

[2] Ekkekakis P, et al. Routledge handbook of physical activity and mental health. London-New York: Routledge; 2013.

[3] Marcus BH, Forsyth LH, Motivating people to be physically active. Champaign: Human Kinetics; 2003.

[4] Buckworth J, Dishman RK. Exercise psychology. Champaign: Human Kinetics; 2002.

[5] Buckley J, Cohen JD, Kramer AF, McAuley E, Mullen SP. Cognitive control in the self-regulation of physical activity and sedentary behavior. Frontiers in Human Neuroscience. 2014;8:747. doi: 10.3389/ fnhum.2014.00747

[6] Mann T, de Ridder D, Fujita K. Self-regulation of health behavior: Social psychological approaches to goal setting and goal striving. Health Psych. 2013;32(5):487-498

[7] De Ridder DT, de Wit JB. Self-regulation in health behavior: Concept, theories and central issues. In: De Ridder DT, de Wit JB, editors. Self-regulation in Health Behavior,London: Wiley; 2006, 1-23.

[8] Knapp DN. Behavioral management techniques and exercise promotion. In: Dishman RK, edi-tor. Exercise adherence. Its impact on public health. Champaign: Human Kinetics; 1988, 203-236.

[9] Sokolowski A, Sagan A. Analysis of data in marketing and public opinion research. In: Examples of statistical inference with the use of Statistica. Warszawa: Statsoft; 1999, 8-12.

[10] Fritz CO, Morris PE, Richler JJ. Effect size estimates: Current use, calculations, and interpretation. J Experimental Psych General. 2011;141(1):2-18.

[11] Shilts MK, Horowitz M, Townsend MS. Goal setting as a strategy for dietary and physical activity behavior change: A review of the literature. Am J Health Promot. 2004;19(2):81-93

[12] Leitner MJ, Leitner SF. Leisure enhancement. London-New York: Routledge; 2004.

[13] Brehm B. Successful fitness motivation strategies. Human Kinetics; 2004. 